\title{
Feminización del magisterio ecuatoriano
}

\author{
Carlos Calderón-Guevara \\ ccalderon@uce.edu.ec \\ https://orcid.org/0000-0002-7408-8733
}

Jesica Pricila Carrera-Pillalazo

jpcarrerap@uce.edu.ec

\section{RESUMEN}

El presente trabajo investigativo se desarrolla alrededor de la problemática de la feminización en el campo de la docencia, con el objetivo principal de explicar el proceso de la feminización del Magisterio ecuatoriano, entendido como el crecimiento del número de mujeres, que llega incluso a ser mayoría. La metodología es de carácter cualitativa con el nivel de profundidad descriptivo, que responde a una investigación documentalbibliográfica. El procesamiento de la información se lo realizó mediante la utilización de la técnica del fichaje y la ficha de trabajo como instrumento para la recolección y análisis de los datos obtenidos. El análisis y discusión de resultados muestra los hallazgos más significativos que se construyen alrededor de la influencia de los roles de género, brechas de desigualdad entre hombres y mujeres en el campo laboral y los aportes más sobresalientes de educadoras ecuatorianas al país. Finalmente, se establecen conclusiones que dan respuesta a la problemática identificada en el estudio realizado.

Palabras clave: roles de género; estereotipos; magisterio; feminización docente; Ecuador. 


\title{
Feminization of the ecuadorian teaching
}

\begin{abstract}
ABSTRAC
The present investigative work is developed around the problem of feminization in the field of teaching, with the main objective of explaining the process of feminization of the Ecuadorian Teaching, understood as the growth of the number of women, which even reaches the majority. The methodology is qualitative in nature with a descriptive level of depth, which responds to a documentary-bibliographical investigation. The processing of the information was carried out through the use of the recording technique and the work sheet as an instrument for the collection and analysis of the data obtained. The analysis and discussion of results shows the most significant findings that are built around the influence of gender roles, inequality gaps between men and women in the labor field and the most outstanding contributions of Ecuadorian educators to the country. Finally, conclusions are established that respond to the problem identified in the study carried out.
\end{abstract}

Keywords: gender roles; stereotypes; teaching; teacher feminization; Ecuador.

Artículo recibido: 15 enero 2022 Aceptado para publicación: 08 febrero 2022 Correspondencia: ccalderon@uce.edu.ec Conflictos de Interés: Ninguna que declarar 


\section{INTRODUCCIÓN}

"Lo más revolucionario que una persona puede hacer es decir siempre en voz alta lo que realmente está ocurriendo."

\section{Rosa Luxemburgo}

El involucramiento de la mujer en el escenario social es sin duda el resultado de un largo proceso inclusivo, donde áreas que en un inicio fueron netamente planteadas como masculinas, con el paso del tiempo perciben una participación de las mujeres que continuamente va en ascenso. La feminización, como afirma Aguilar (2011) “connota una acción”, «el proceso de volverse más femenino»o «más común»o «extendido entre las mujeres»" (p. 129). Paulatinamente los aportes de las mujeres toman más fuerza y son más reconocidos, pues en sectores clave como la salud y la educación su incidencia es mayor al representar a la mayor cantidad de personas que ejercen actividades afines.

La educación para León (2007) "presupone una visión del mundo y de la vida, una concepción de la mente, del conocimiento y de una forma de pensar; una concepción de futuro y una manera de satisfacer las necesidades humanas” (p. 598). La educación es uno de los principales derechos que tiene el ser humano, pues es base fundamental para su desarrollo y una manera eficaz para reducir los niveles de pobreza, así como la mejora en materia de igualdad, la salud, la paz y estabilidad (Banco Mundial, 2018, p. 1). La educación tiene un sentido histórico social, responde a realidades concretas de una época específica, sus características no únicamente se ven reflejadas en el campo pedagógico sino en toda la realidad socioeducativa inmersa. Es en este escenario donde la actividad docente se construye como un espacio sujeto a varios cambios, desde sus estructuras formacionales hasta la concepción misma de la profesión.

El propósito de este artículo es analizar las causas o factores qué producen la feminización de la profesión docente en el Ecuador, crear un puente entre la feminización y la docencia, al comprender el carácter cambiante del involucramiento de las mujeres en las filas del Magisterio nacional. Por este motivo se plantea encontrar respuestas a la pregunta central: ¿Porque existe feminización dentro del Magisterio ecuatoriano?

En este sentido se busca relacionar los factores que generan el proceso de feminización de la docencia, que devela y profundiza la problemática en el contexto de la sociedad ecuatoriana. 
Es importante precisar las limitaciones del estudio, particularmente referido a su alcance y profundidad, pues al tratarse de una investigación documental, se tiene como desventaja que la información obtenida sea limitada, es decir no estén disponibles para confrontarlos teóricamente o para reforzar el argumento de los investigadores.

En cuanto a la estructura y contenido del artículo, en la sección 2 se presenta los conceptos relacionados con la investigación. En la sección 3, se especifica la metodología del estudio. En la sección 4 se realiza análisis y discusión de resultados, y finalmente, en la sección 5, se establecen las conclusiones de acuerdo con los resultados obtenidos.

\subsection{Conceptos relacionados}

El abordaje inicial sobre el tema central de la feminización en el campo docente debe comenzar desde la caracterización de elementos fundamentales para su adecuada comprensión, como son estereotipos de género, roles y etiquetas sociales. Para Cook \& Cusack (2009) "los estereotipos de género hacen referencia a la construcción o comprensión de los hombres y las mujeres, debido a la diferencia entre sus funciones físicas, biológicas, sexuales y sociales” (p. 2). En este sentido, dichas diferenciaciones marcan una línea específica de comportamiento, pues se concibe a un individuo enmarcado en características determinadas dependiendo de su sexo de nacimiento, de esta manera se limita el accionar y la apreciación integral de la persona como ser humano.

Se debe tomar en consideración que los estereotipos van de la mano con los prejuicios, los cuales despiertan comportamientos degradantes que afectan directamente a las personas; mujeres y hombres son víctimas constantes de la estereotipación, que a su vez desemboca en la generación de limitaciones en distintos aspectos, educativos, laborales, participativos, entre otros.

Sobre los roles de género Herrera (2000) señala que "a lo largo del desarrollo de la sociedad los individuos fueron aprendiendo, a través del proceso de socialización, el comportamiento que cada uno debe asumir según fuera hombre o mujer” (p. 568). Así el comportamiento de una persona se construye de manera social, lo positivo, lo negativo, lo correcto e incorrecto, lo "esperado" se transforma en sinónimo de la acumulación de características normalizadas a lo largo del tiempo.

Como último elemento, Kaplan (2009) afirma que "las etiquetas o pre-juicios (juicios previos, tácitos) se asocian al proceso de estigmatización y funcionan allí como metáforas sociales que simbolizan lo marginal" (p. 17). Las etiquetas tienen la tarea irrefutable de 
segmentar y englobar a las personas por rasgos compartidos, de esta manera se generan grupos superiores e inferiores, grupos con posibilidades y grupos con limitaciones; lo marginal se atañe a los grupos menos favorecidos que se mueven contra corriente, profesando actitudes diferentes y fuera de lo normal.

Es necesario que se realice un análisis de estos tres elementos mencionados, las etiquetas, los roles y los estereotipos; como es que se han posicionado de manera casi invisible pero ejerciendo a su vez un poder sorprendente dentro de toda sociedad, en la toma de decisiones, en lo económico, laboral, político, educativo, cultural, en fin, en cada aspecto de vida de los seres humanos; el cuestionamiento llega al momento de preguntarnos si es correcto continuar con las concepciones aceptadas como "normales" como si fuesen la única respuesta y dejar de lado caminos diferentes.

\section{Tabla 1}

Estereotipos de género, roles de género y etiquetas sociales

\begin{tabular}{|c|c|c|c|}
\hline & Concepción & $\begin{array}{l}\text { Ejemplo para } \\
\text { hombre }\end{array}$ & $\begin{array}{c}\text { Ejemplo para } \\
\text { mujer }\end{array}$ \\
\hline $\begin{array}{l}\text { Estereotipos de } \\
\text { género }\end{array}$ & $\begin{array}{l}\text { Caracterizaciones } \\
\text { sociales y culturales que } \\
\text { se construyen a través del } \\
\text { tiempo e historia tanto } \\
\text { para hombres como para } \\
\text { mujeres. }\end{array}$ & $\begin{array}{l}\text { Los hombres no } \\
\text { lloran. }\end{array}$ & $\begin{array}{l}\text { Las mujeres } \\
\text { siempre son } \\
\text { delicadas y } \\
\text { consideradas. }\end{array}$ \\
\hline Roles de género & $\begin{array}{l}\text { Comportamiento que se } \\
\text { espera debe tener una } \\
\text { persona de manera } \\
\text { diferenciada sea hombre } \\
\text { o mujer dentro de las } \\
\text { normas sociales } \\
\text { establecidas. Momento } \\
\text { en el que se ejerce los } \\
\text { lineamientos de los } \\
\text { estereotipos de género. }\end{array}$ & $\begin{array}{l}\text { Los hombres no } \\
\text { deben llora, eso es } \\
\text { para mujeres. }\end{array}$ & $\begin{array}{c}\text { Las mujeres no } \\
\text { deben hablar } \\
\text { groserías. }\end{array}$ \\
\hline $\begin{array}{l}\text { Etiquetas } \\
\text { sociales }\end{array}$ & $\begin{array}{llr}\text { Concepción, } & \text { y } \\
\text { catalogación que la } \\
\text { sociedad tiene ante un } \\
\text { individuo o grupo de } \\
\text { individuos. }\end{array}$ & $\begin{array}{l}\text { "Actúas como } \\
\text { mujer" }\end{array}$ & "Marimacho" \\
\hline
\end{tabular}

Fuente: Elaboración propia 
En la Tabla 1 se sintetiza y ejemplica los estereotipos de género, roles y etiquetas sociales que evidencian las concepciones y prácticas equivocadas con relación a hombres y mujeres.

Abduca, Pérez \& Ainora (2007) afirman que "todo lo que es conforme a la regla o a los preceptos de la autoridad está bien, todo lo que no se ajusta a estas condiciones, está mal, no hay disociación entre bien y el deber" (p. 5). Según este criterio, es pertinente entender que encasillar al ser humano en categorías preestablecidas en base a suposiciones altera su desarrollo socio emocional; adicionalmente, cuando no se siguen las reglas ya establecidas a nivel de la sociedad se dará un fenómeno de rechazo y ridiculización de esas personas.

\subsection{Feminización de las profesiones}

El mercado laboral se encuentra en un cambio constante al adquirir matices modernos que responden a necesidades de la sociedad vigente. Vásquez (2010) asegura que la feminización evidencia modificaciones en las diferentes profesiones donde la incorporación de mujeres es palpable (p. 12). En este sentido la incorporación de mujeres en las distintas profesiones supone cambios estructurales que significan la feminización de las mismas.

La feminización de las profesiones es un apartado que se puede analizar dentro de dicho mercado laboral. Ocupaciones y profesiones que en el pasado tenían una participación total masculina cambian y se observa que en la actualidad la participación de mujeres aumenta; así, campos como el ejército y seguridad, que por mucho tiempo se guardaba para ser exclusivamente masculina, ya cuenta con elementos femeninos que realizan un desempeño sobresaliente; de la misma manera, la salud, donde portar el simbólico mandil de médico únicamente era privilegio para hombres, con el paso del tiempo crece el número de mujeres que se abren campo y sobresalen en la labor que realizan; la educación también es una ejemplificación bastante clara del paulatino ingreso de mujeres, donde la facultad de impartir clases quedaba exclusivamente en manos masculinas y en días actuales el grupo docente femenino es mayor al setenta por ciento del total de docentes a nivel nacional.

Ahora bien, la inserción de la mujer en el mundo laboral es el resultado de un sinnúmero de condiciones y exigencias económicas, políticas, sociales y culturales que jugaron en pro de la inclusión femenina, expresándose más acelerado el proceso en los últimos años, 
ya que se quiebra los estigmas que marcaban el dinamismo de los pueblos arraigados en las características "adecuadas" que se correspondía a las mujeres y a los hombres. Como afirman Macías \& Cedeño (2014):

Las mujeres son formadas con una ideología que sustenta su inferioridad y dependencia de los hombres y que plantea como valores fundamentales de su género la pasividad, la delicadeza, la ternura, la debilidad física y psicológica, la sumisión y obediencia, base de sus roles tradicionales de esposa y madre; muy contrarios a la fuerza, la agresividad, la competencia, la fortaleza corporal y psicológica, considerados valores intrínsecos y natos de los hombres, basados en sus roles de género como eran garantizar el sustento económico de la familia y la defensa del patrimonio. (p. 2)

Los cambios que el mundo ha sufrido y los roles cambiantes que las personas han adquirido se lo puede percibir claramente en el cambio del feudalismo al capitalismo; mientras que el feudalismo elevó en gran medida el rol protagónico de los hombres como afirman Macías y Cedeño, su fortaleza corporal y mental, así como el elevado sentido de competitividad se consideraron como características únicas para la supremacía masculina, ante la delicadeza, pasividad, sumisión y obediencia cultivada en las mujeres. Pero con el cambio de modo de producción al capitalista entra en escena una nueva forma de concepción social, donde se abren más formas de sustento que las conocidas tradicionalmente, por tal motivo vacantes que poco a poco quedan libres son asumidas bajo tutela femenina, aunque no bajo las mismas condiciones o privilegios anteriores. La creación de fábricas provee de puestos de trabajos a hombres tanto del campo como de la ciudad ofreciéndoles un mejor pago, aunque con tratos más crudos.

Si bien es cierto el ingreso de mujeres no se realizó de manera inmediata, con el paso de los años es posible ver como las actividades en su gran mayoría son compartidas entre hombres y mujeres. Esto no quiere decir que nos encontremos en un estado de equilibrio o bienestar absoluto, pues aún falta mucho trabajo para hablar de un mercado laboral ecuatoriano equitativo y en condiciones óptimas en materia inclusiva, particularmente por el carácter del Estado y sociedad ecuatoriana.

A continuación, se muestra una serie de cifras a modo de estadísticas de la realidad situacional ecuatoriana, de manera específica se toma como referencia el libro Mujeres y 
Hombres del Ecuador en cifras III donde, se presenta la población ecuatoriana dividida en ramas de actividad en torno al género.

\section{Tabla 2}

Población ocupada, según rama de actividad

\begin{tabular}{|c|c|c|}
\hline Rama de actividad & Mujeres (\%) & Hombres (\%) \\
\hline Hogares privados con servicio doméstico & 94,1 & 5,9 \\
\hline Actividades de Servicios sociales y de salud & 68,3 & 31,7 \\
\hline Hoteles y restaurantes & 65,8 & 34,2 \\
\hline Enseñanza & 61,9 & 38,1 \\
\hline $\begin{array}{l}\text { Otras actividades comunitarias, sociales } y \\
\text { personales }\end{array}$ & 60,2 & 39,8 \\
\hline Organizaciones y órganos extraterritoriales & 53,4 & 46,6 \\
\hline Comercio, reparación vehicular & 51,5 & 48,5 \\
\hline Intermediación financiera & 49,6 & 50,4 \\
\hline Industrias manufactureras & 37,2 & 62,8 \\
\hline Actividades inmobiliarias, empresariales y alquiler & 32,6 & 67,4 \\
\hline Agricultura, ganadería, caza y silvicultura & 30,8 & 69,2 \\
\hline Administración pública y defensa; seguridad socia & 29,7 & 70,3 \\
\hline Suministros de electricidad, gas y agua & 22,6 & 77,4 \\
\hline Pesca & 11,4 & 88,6 \\
\hline Transporte, almacenam. y comunicaciones & 11.0 & 89,0 \\
\hline Explotación de minas y canteras & 9,7 & 90,3 \\
\hline Construcción & 5,3 & 94,7 \\
\hline
\end{tabular}

Fuente: Ferreira et al. (2014) Mujeres y Hombres del Ecuador en cifras III

En la Tabla 2, los porcentajes de participación masculina y femenina es diversa, pues según el tipo de actividad las cifras cambian, por ejemplo, los servicios domésticos corresponden al 94,1\% de mujeres, caso contario ocurre en la construcción, donde el 94,7\% corresponde únicamente a hombres. Estos casos en particular son los polos más opuestos en la lista de actividades presentada al variar enormemente el grado de involucramiento dependiendo del género.

$\mathrm{Si}$ se recuerda las características que se atañe tanto a hombres como a mujeres específicamente, es posible reconocer que dichas características guardan estrecha relación con las cifras anteriores. Por ejemplo, las mujeres por "naturaleza" son consideradas 
delicadas, serviciales, cariñosas, empáticas, responsables, en fin, madres y esposas; así las ramas de actividad con predominancia femenina son de servicio doméstico, servicios sociales y salud, hoteles, restaurantes, enseñanza, actividades comunitarias y sociales. La interrelación presente no hace más que aseverar que, aunque la intensidad de los estereotipos y etiquetas sociales no es tan palpable a simple vista, se encuentra presente de manera constante en el mercado de trabajo del país.

\subsubsection{Inclusión femenina en el mercado laboral}

El mercado de trabajo está compuesto por una infinidad de ofertas laborales, las cuales para poder ocuparlas muestran varios aspectos a ser considerados; es en este punto donde se percibe la llamada brecha de desigualdad, ya que no todas las personas están en la capacidad de cumplir con los requerimientos solicitados. Dichos requisitos varían dependiendo del cargo y el lugar que se aspira; pueden ser desde el plano académico y formativo, aptitudes natas del participante, condiciones físicas, condiciones socioculturales, familiares, de género, entre otros.

Comprender lo que significa la inclusión es el primer paso para abordar el tema de la feminización de la profesión docente en un escenario inclusivo. Como afirma Saleh (2005):

La inclusión es un proceso, una interminable búsqueda de la comprensión y respuesta a la diversidad en la sociedad. La inclusión no es una estrategia para ayudar a las personas para que calcen dentro de sistemas y estructuras existentes; es transformar esos sistemas $\mathrm{y}$ estructuras para que sean mejores para todos. (p. 16)

La inclusión se la puede comprender como un proceso en el cual todas las personas sin importar su situación económica, género, etnia, gustos y preferencias son capaces de integrarse en iguales condiciones, en alguna actividad de la sociedad. Cabe recalcar que la inclusión puede ser diferente dependiendo del momento y de las condiciones reales y concretas, de esta manera es posible que una empresa, país, o ciudad se encuentre más avanzada en materia inclusiva que otra, lo importante es que se continúe con la exigencia, construcción, perfeccionamiento y fortalecimiento de este esencial derecho humano.

Como afirman Rodríguez \& Monllau (2012) "Las políticas de igualdad han tenido éxito en los procesos de incorporación femenina al mercado laboral, pero no han servido para alterar la distribución desigual de la carga de trabajo entre hombres y mujeres" (p. 82). 
La integración numérica de mujeres al ámbito laboral es el primer paso para una sociedad más inclusiva, a pesar de ello, no significa que sus labores en el campo doméstico disminuyan, por el contrario, han aumentado en una doble o triple jornada laboral, situación que no se presenta en los hombres.

Las brechas de género según Vaca (2019) ocasionan que las mujeres posean una taza de participación de empleo en sectores vulnerables. Además, existen patrones culturales patriarcales que producen un relego de mujeres al ámbito doméstico, lo que a su vez resulta en una sobre carga laboral no remunerada e injusta.

Los retos que las mujeres deben experimentar en el competitivo mercado laboral atraviesan por dos filtros, el primero con las limitaciones generales que se pueden encontrar, como la poca oferta y alta demanda de puestos de trabajos, las políticas estatales y los requerimientos empresariales; el segundo filtro está ligado a su condición de mujer, la situación se agudiza pues se ve en la obligación de equilibrar lo laboral, lo personal y lo familiar, al asumir las cargas como propias.

\subsection{Feminización en la docencia}

En párrafos anteriores se abordó el tema de la feminización como tal y la feminización de las profesiones, ahora es momento de centrarse en la feminización de la docencia. La docencia presenta matices marcados en cuanto a la inclusión femenina, pues si revisamos la historia, en un inicio la educación y sus instituciones estaba en manos de la iglesia católica y únicamente de docentes hombres. Es en el periodo liberal en el Ecuador, con la presencia del General Eloy Alfaro, que se concibe el ingreso paulatino de mujeres al Magisterio con la creación de los Colegios Normales Juan Montalvo y Manuela Cañizares, que tenían como finalidad la formación integral de profesoras quienes podían cubrir la creciente demanda educativa nacional. De esta manera, las mujeres no únicamente asisten a las aulas de clase para aprender, sino que asisten tomando el rol de mentoras; está claro que no fue un inicio sencillo, ya que la valía y estima social no estaba en una buena posición, pero con esfuerzo y dedicación la idea novedosa, extraña y atrevida de ver a una mujer impartiendo clases, se transforma en algo común y aceptado. Es necesaria la implementación de acciones en pro de un desarrollo social sostenible, donde la inclusión de las mujeres sea desde la primera instancia en los niveles educativos, para consecuentemente involucrarse de manera real, justa y segura en el mercado laboral, así como en espacios públicos (Gil, 2016, p. 27). Las mujeres deben inmiscuirse en el 
campo educativo desde las primeras etapas de su desarrollo, en el caso de Ecuador desde los niveles inicial y básico; lo cual implica trabajar con un enfoque de género en base a la igualdad, equidad y liberación, dado que, al encontrase en desventaja social les permitirá hacer frente en mejores condiciones en el mundo laborar y en la esfera pública. La feminización universitaria es comprendida como un fenómeno relacional, pues como afirma Graña (2008) "su contexto más inmediato lo constituyen las relaciones entre géneros, y luego, el sociohistórico: las grandes transformaciones ocurridas en el siglo XX en lo concerniente a los roles que la sociedad asigna a hombres y mujeres" (p. 81). Las fuerzas femeninas docentes no únicamente se conforman con ocupar la primaria y secundaria, es necesario tomar círculos académicos más valorados e influyentes, así la universidad abre sus puertas no únicamente a estudiantes, sino a docentes catedráticas universitarias en respuesta a los acelerados cambios del siglo XX en pro de la modernidad. Es necesario mostrar en cifras el paulatino aumento de mujeres en la docencia a través de los años. A continuación, se muestran dos tablas con cifras de las últimas décadas, desde el período 1993-1994 hasta el período 2019-2020 diferenciando el número y porcentaje de docentes por género.

\section{Tabla 3}

Total de docentes por sexo desde el período1993-1994 hasta el período 2005-2006

\begin{tabular}{ccccccc}
\hline Período & $\begin{array}{c}\text { Profesores } \\
\text { hombres }\end{array}$ & $\begin{array}{c}\text { Profesoras } \\
\text { mujeres }\end{array}$ & Total & $\begin{array}{c}\text { \% Profesores } \\
\text { hombres }\end{array}$ & $\begin{array}{c}\text { \%Profesoras } \\
\text { mujeres }\end{array}$ & $\begin{array}{c}\text { \% } \\
\text { Total }\end{array}$ \\
\hline $1993-1994$ & 55022 & 75095 & 130117 & 42 & 58 & 100 \\
$1994-1995$ & 57385 & 81133 & 138518 & 41 & 59 & 100 \\
$1995-1996$ & 60617 & 86255 & 146872 & 41 & 59 & 100 \\
$1996-1997$ & 65085 & 91595 & 156680 & 42 & 58 & 100 \\
$1997-1998$ & 66990 & 95810 & 162800 & 41 & 59 & 100 \\
$1999-2000$ & 71649 & 104679 & 176328 & 41 & 59 & 100 \\
$2000-2001$ & 72066 & 107518 & 179584 & 40 & 60 & 100 \\
$2001-2002$ & 71783 & 110163 & 181946 & 39 & 61 & 100 \\
$2002-2003$ & 73770 & 114227 & 187997 & 39 & 61 & 100 \\
$2003-2004$ & 75025 & 117823 & 192848 & 39 & 61 & 100 \\
$2004-2005$ & 75548 & 119439 & 194987 & 39 & 61 & 100 \\
$2005-2006$ & 76777 & 123319 & 200096 & 38 & 62 & 100 \\
\hline
\end{tabular}

Nota: No existe información del período 1998-1999. Fuente: Elaboración propia con base en (Ministerio de Educación, 2021) 


\section{Tabla 4}

Total de docentes por sexo desde el período 2009-2010 hasta el período 2019-2020

\begin{tabular}{ccccccc}
\hline Período & $\begin{array}{c}\text { Profesores } \\
\text { hombres }\end{array}$ & $\begin{array}{c}\text { Profesoras } \\
\text { mujeres }\end{array}$ & Total & $\begin{array}{c}\text { \% } \\
\text { Profesores } \\
\text { hombres }\end{array}$ & $\begin{array}{c}\text { \%Profesoras } \\
\text { mujeres }\end{array}$ & \% Total \\
\hline $2009-2010$ & 76341 & 153350 & 229691 & 33 & 67 & 100 \\
$2010-2011$ & 79822 & 161334 & 241156 & 33 & 67 & 100 \\
$2011-2012$ & 77728 & 160309 & 238037 & 33 & 67 & 100 \\
$2012-2013$ & 74283 & 156396 & 230679 & 32 & 68 & 100 \\
$2013-2014$ & 70268 & 157755 & 228023 & 31 & 69 & 100 \\
$2014-2015$ & 70493 & 162897 & 233390 & 30 & 70 & 100 \\
$2015-2016$ & 66265 & 154835 & 221100 & 30 & 70 & 100 \\
$2016-2017$ & 64134 & 153177 & 217311 & 30 & 70 & 100 \\
$2017-2018$ & 64090 & 155961 & 220051 & 29 & 71 & 100 \\
$2018-2019$ & 63516 & 158849 & 222365 & 29 & 71 & 100 \\
$2019-2020$ & 62695 & 158288 & 220983 & 28 & 72 & 100 \\
\hline
\end{tabular}

Nota: No existe información de los periodos 2006-2007, 2007-2008 y 2008-2009

Fuente: Elaboración propia con datos publicados por el (Ministerio de Educación, 2021)

Las Tablas 3 y 4 muestran cómo año tras año el número de docentes mujeres se incrementa en comparación con el de los hombres. De esta manera, hasta el período 20192020 que es el último período que se presenta registro por parte del Ministerio de Educación, las mujeres superan el setenta por ciento de la totalidad de docentes a nivel del país.

Este fenómeno genera una interrogante central, ¿cuál es el motivo para que cada período se perciba un aumento femenino dentro de las filas docentes? Es pertinente que se encuentre el origen y las consecuencias principales que abrazan a la feminización docente del Magisterio ecuatoriano.

Para dar respuesta a esta pregunta, se debe partir desde la concepción misma de la feminización docente y comprenderla, capaz de generar situaciones relacionantes en sus causas y efectos. Dicho esto, aunque se habla de "logros" en la inserción femenina en diferentes aristas sociales, la feminización tan latente y marcada tiene un "lado oscuro", como por ejemplo la relación directa con la feminización de la pobreza, donde se destacan las condiciones que se prestan para que dicha feminización sea posible de desarrollar. 
Existen factores como la desvalorización de la profesión docente que va de la mano con la feminización de la misma, pues al ser ocupado en su mayoría por mujeres, se comienza a creer que es una profesión que no requiere mayoritariamente de esfuerzo o que no se necesita una especialización para ejercerla, si se lanza una mirada hacia el pasado se reconoce la elevada estima que un docente poseía.

Otro de los factores a tomar en cuenta, se presenta en la inclinación femenina al estudio de carreras humanas, donde ya sea por la mal llamada naturaleza femenina, hablando de las características socialmente construidas el rededor de una mujer, la cercanía de la actividad o la posibilidad de equilibrar las aspiraciones profesionales con las personales sin sufrir el relego social, se suman y encajan perfectamente para el aumento progresivo femenino.

El mercado laboral también juega un papel fundamental en la incidencia femenina docente, pues como se mencionó anteriormente, las condiciones en su mayoría desiguales conllevan a una toma de decisiones masivas hacia algo específico que permita a las personas un ingreso en el dinámico mundo laboral; ligado a esto está el tema de la remuneración, que en el caso del Magisterio ecuatoriano se encuentran congelados alrededor de diez años, por lo que, aún existen varios aspectos que deberían ser puestos sobre la mesa de discusión, pues la sobrecarga laboral y la responsabilidad que conlleva el ser docente no corresponde con el salario que percibe frente a la intensa actividad y labor educativa que cumple.

En este contexto, la situación del Magisterio ecuatoriano se agravó durante la pandemia, como afirman Calderón, C., Racines, M., Castañeda, G. y Rodríguez, F. (2021) “obligó a las y los docentes al confinamiento y al trabajo virtual, afectando sus condiciones laborales y calidad de vida; lo que se evidencia en la alteración de sus hábitos cotidianos, pues pasa en casa todo el tiempo; sobre carga laboral, ya que cumple más horas de su jornada habitual en planificación, elaboración de informes, reuniones institucionales, atención a estudiantes y padres de familia a cualquier hora del día.” (p. 21)

El análisis de las causas y/o consecuencias mencionadas deben ser comprendidas como un proceso dialéctico. Así, lo concebido inicialmente como una causa puede convertirse en una consecuencia dependiendo del caso específico, pues las condiciones y realidades son completamente diferentes. Entonces, a modo de ejemplo, la distribución de docentes en los niveles de enseñanza se puede comprender como una causa pues la feminización 
docente parte de la desigual cantidad de docentes por género, o como un efecto, resultado de la feminización misma.

La educación junto con la salud sin duda, son las áreas prioritarias que más se les debería prestar atención, particularmente en lo educativo, se debe procurar espacios libres de prejuicios encaminados a la mejora constante y cuidado de todos sus actores, generar conciencia sobre la importancia del ingreso, permanencia y culminación de los estudiantes dentro del sistema educativo; construcción de planes, programas y proyectos educativos coherentes que respondan al contexto socioeconómico de cada región y a las necesidades sociales y personales de toda la comunidad educativa; en fin, la educación debe manejarse con suma responsabilidad y compromiso por parte del Estado y de quienes dirigen el área educativa.

Ahora bien, el panorama utópico educativo donde todos son tratados en condiciones igualitarias, donde existen toda clase de recursos para desarrollar el proceso educativo en las mejores condiciones y finalmente contar con la corresponsabilidad compartida entre docentes, estudiantes, padres de familia y la sociedad en general es un escenario lejos de la realidad, principalmente por el carácter desigual, inequitativo y discriminatorio de la sociedad ecuatoriana.

Una de las actividades más transcendentales para el desarrollo de la sociedad y formación humana es la docencia, sin embargo, de manera permanente ha sido desvalorizada social y económicamente. Para la Organización de las Naciones Unidas para la Cultura, las Ciencias y la Educación (UNESCO, 2013) "Los docentes representan una de las fuerzas más sólidas e influyentes con miras a garantizar la equidad, el acceso y la calidad de la educación. Ellos son la clave del desarrollo mundial sostenible” (p. 1). Por este motivo, la creación de condiciones y espacios inclusivos son fundamentales, esto en cierto grado, se cumple con las y los estudiantes, ya que la mayor parte de la atención se vuelca sobre ellos, como sujetos conscientes del proceso de enseñanza y aprendizaje; situación que no ocurre con las y los docentes, que a su alrededor se han configurado intencionalmente fuertes líneas de estigma desde su proceso inicial de formación, posterior ingreso al Magisterio, condiciones salariales y desempeño profesional. Por tal razón, si educadoras y educadores tienen estos inconvenientes como se espera que el proceso educativo no presente un desequilibrio y favoritismos. 
Uno de los aspectos que más salta a la vista es la desigual distribución de docentes por género en los distintos niveles que oferta la educación ecuatoriana. Aún si mayoritariamente el cuerpo docente nacional es ocupado por mujeres, la distribución resalta algunos elementos a considerar. Se presenta una tabla con datos del fin del período 2019-2020. Para el análisis se toma en consideración únicamente tres niveles: inicial, básica media y bachillerato.

En general en el sector público, si bien hombres y mujeres tienen igual remuneración, esto no es lo que frecuentemente sucede en los establecimientos privados, donde se evidencian grandes desigualdades salariales.

\section{Tabla 5}

Total de docentes por sexo a nivel nacional agrupados por nivel educativo

\begin{tabular}{|c|c|c|c|c|c|c|}
\hline No. & Nivel de educación & $\begin{array}{l}\text { Docentes } \\
\text { mujeres }\end{array}$ & $\begin{array}{l}\text { Docentes } \\
\text { hombres }\end{array}$ & $\begin{array}{c}\text { Total } \\
\text { docentes }\end{array}$ & $\begin{array}{c}\% \\
\text { Docentes } \\
\text { mujeres }\end{array}$ & $\begin{array}{c}\% \\
\text { Docentes } \\
\text { hombres }\end{array}$ \\
\hline 1 & Alfabetización & 13 & 9 & 22 & $59 \%$ & $41 \%$ \\
\hline 2 & Artesanal & 38 & 4 & 42 & $90 \%$ & $10 \%$ \\
\hline 3 & Bachillerato & 459 & 472 & 931 & $49 \%$ & $51 \%$ \\
\hline 4 & Bachillerato y Artesanal & 5 & 0 & 5 & $100 \%$ & $0 \%$ \\
\hline 5 & Educación Básica & 13200 & 5200 & 18400 & $72 \%$ & $28 \%$ \\
\hline 6 & Educación Básica y Alfabetización & 45 & 22 & 67 & $67 \%$ & $33 \%$ \\
\hline 7 & Educación Básica y Artesanal & 50 & 20 & 70 & $71 \%$ & $29 \%$ \\
\hline 8 & $\begin{array}{l}\text { Educación Básica, Alfabetización y } \\
\text { Artesanal }\end{array}$ & 1 & 0 & 1 & $100 \%$ & $0 \%$ \\
\hline 9 & $\begin{array}{l}\text { Educación Básica, Bachillerato y } \\
\text { Alfabetización }\end{array}$ & 25 & 12 & 37 & $68 \%$ & $32 \%$ \\
\hline 10 & $\begin{array}{l}\text { Educación Básica, Bachillerato y } \\
\text { Artesanal }\end{array}$ & 135 & 88 & 223 & $61 \%$ & $39 \%$ \\
\hline 11 & $\begin{array}{l}\text { Educación Básica, Bachillerato, } \\
\text { Alfabetización y Artesanal }\end{array}$ & 17 & 7 & 24 & $71 \%$ & $29 \%$ \\
\hline 12 & EGB y Bachillerato & 26253 & 16279 & 42532 & $62 \%$ & $38 \%$ \\
\hline 13 & Inicial & 3783 & 77 & 3860 & $98 \%$ & $2 \%$ \\
\hline 14 & Inicial y Bachillerato & 101 & 53 & 154 & $66 \%$ & $34 \%$ \\
\hline 15 & Inicial y EGB & 42973 & 10029 & 53002 & $81 \%$ & $19 \%$ \\
\hline 16 & $\begin{array}{l}\text { Inicial, Educación } \\
\text { Bachillerato }\end{array}$ & 68039 & 28758 & 96797 & $70 \%$ & $30 \%$ \\
\hline
\end{tabular}

Fuente: Elaboración propia con base datos de Dirección de Análisis e información Educativa, Coordinación General de Planificación, Ministerio de Educación, (2021) 
En el contenido de la Tabla 5, se evidencia que la participación de mujeres docentes va reduciéndose según el nivel educativo, mientras en el nivel inicial hay una prevalencia casi absoluta, en la educación básica disminuye de manera significativa y, en bachillerato, aunque la diferencia es mínima, los docentes hombres tienen mayor porcentaje.

Ahora bien, más allá de solamente comprender las cifras, es necesario analizar el trasfondo de esta problemática. Mujeres y hombres cultural y socialmente se diferencian y adquieren características marcadas como se abordó anteriormente, dichas características se mantienen hasta lo más profundo de la sociedad. Enmarcados en esto, la educación inicial que básicamente es el inicio del sistema educativo nacional y tiene bajo su responsabilidad el cuidado de infantes, muestra casi la totalidad de docentes mujeres, donde apenas el 2\% corresponde a hombres. Como afirman Cappi et al. (2018) "Asumir la educación infantil como perteneciente al mundo femenino también limita el ingreso de hombres en la carrera de Pedagogía. El reducido número de docentes del sexo masculino es resultante de múltiples factores relacionados con la legitimación cultural” (p. 91). Es clara la razón, culturalmente el cuidado y crianza de niños, al menos en edades tempranas siempre ha sido responsabilidad de las madres o hermanas mayores, así esta "costumbre" se mantiene, este fenómeno acarrea un problema oculto en el cual hombres se ven relevados y limitados del ejercicio de esta labor, pues no se ve "correcto" que hombres cuiden a niños pequeños.

Para complementar lo dicho anteriormente, Almeida \& de la O Barroso (2020) destacan: La equidad de género, en docentes universitarias, se encuentra atravesada por una serie de factores, tanto visibles como invisibles, que limitan el desarrollo de las mujeres, especialmente en ámbitos en los cuales su nivel de participación es bajo, como la investigación y la dirección de la universidad. Existe un marcado dominio de los hombres, que resulta contraproducente en un espacio considerado generador de conocimiento, compromiso con la sociedad, igualitario y no reproductor de las desigualdades. (p. 105)

Las autoras ponen especial atención en la distribución desigual de responsabilidades que existe dentro de la docencia universitaria. Responsabilidades que en la mayoría son ocupadas por hombres como es la investigación y la dirección universitaria; todo en 
contraposición a espacios igualitarios, pues las brechas son muy marcadas y limitan el desarrollo profesional de las docentes.

El análisis no termina ahí, pues, según se avanza en los niveles educativos hasta llegar al, postgrado y doctorado, se va mermando la intervención femenina, como asevera Araya (2004) “en los niveles de preescolar y de primaria, la gran mayoría de docentes son mujeres; no obstante, la proporción de estas disminuye a medida que aumenta la edad de las alumnas y alumnos y el prestigio social de cada ciclo escolar" (p. 6). La desigual participación de profesores en los distintos niveles educativos del país junto con el continuo involucramiento femenino a lo largo de los años se relaciona directamente con la desvalorización docente, al ser puntos dinamizantes en la llamada feminización docente. En buena medida, la educación de los más pequeños está en manos de maestras (mujeres) porque se ve como extensión del trabajo del cuidado doméstico; por ello son mayoría absoluta entre los niveles con niños y niñas, situación que se reduce en niveles de bachillerato y en universidad.

\subsection{Aporte de mujeres docentes ecuatorianas}

Aportes en pro de la educación existen varios, es gratificante encontrar información y bases que contribuyen con el quehacer educativo, pero ¿qué tan común es encontrar a mujeres que aporten en esta área? Y más aún ¿qué tan común es encontrar aportes de educadoras ecuatorianas? Sin embargo, que la fuerza docente es mayoritariamente femenina no se escucha de investigaciones y aportes de mujeres docentes; es necesario reconocer su participación es protagónica en proyectos de investigación educativa, en funciones directivas y sobre todo como maestras de aula con un perfil innovador, crítico y creativo con propuestas para una educación diferente, democrática y emancipadora; se hace necesario generar espacios para su difusión y reconocimiento social y profesional.

A lo largo de la historia ecuatoriana se han gestado mujeres símbolo que han contribuido con la sociedad, no únicamente en la educación, sino a favor de varias áreas vinculadas como son los derechos humanos, medio ambiente, inclusión, interculturalidad y su propio reconocimiento femenino. Se presenta una tabla que contiene el aporte de algunas mujeres pioneras en Ecuador. 


\section{Tabla 6}

Aportes de educadoras ecuatorianas

\begin{tabular}{|c|c|c|c|}
\hline No & Nombre & $\begin{array}{c}\text { Área } \\
\text { desempeñada }\end{array}$ & Aporte a la sociedad ecuatoriana \\
\hline 1 & $\begin{array}{l}\text { Aurora Estrada y } \\
\text { Ayala (1901-1967) }\end{array}$ & $\begin{array}{l}\text { Educadora, } \\
\text { poeta, } \\
\text { escritora }\end{array}$ & $\begin{array}{l}\text { Presidió la Unión de Mujeres del Guayas } \\
\text { (1955). } \\
\text { Dictó conferencias a favor de los Derechos } \\
\text { Humanos. }\end{array}$ \\
\hline 2 & $\begin{array}{l}\text { Blanca Martínez } \\
\text { Mera (1897-1976) }\end{array}$ & $\begin{array}{l}\text { Docente, } \\
\text { escritora, } \\
\text { política }\end{array}$ & $\begin{array}{l}\text { La paz en el campo, primera mujer en publicar } \\
\text { una novela en Ecuador. } \\
\text { Rectora del Normal "Manuela Cañizares". } \\
\text { Vicecónsul en Boston. }\end{array}$ \\
\hline 3 & $\begin{array}{l}\text { Dolores Cacuango } \\
(1881-1971)\end{array}$ & $\begin{array}{l}\text { Líder } \\
\text { indígena, }\end{array}$ & $\begin{array}{l}\text { Activista defensora de derechos indígenas. } \\
\text { Fundadora de la Federación Indígena } \\
\text { ecuatoriana (FEI) (1944). } \\
\text { Cofundadora de las primeras escuelas } \\
\text { indígenas, se implementó la educación en } \\
\text { quichua y saberes ancestrales. }\end{array}$ \\
\hline 4 & $\begin{array}{l}\text { Dolores Josefina } \\
\text { Torres (1897-1955) }\end{array}$ & Maestra & Precursora de la educación pública en Cuenca. \\
\hline 5 & $\begin{array}{l}\text { Elisa Ortiz Garcés } \\
(1906-1991)\end{array}$ & $\begin{array}{l}\text { Pedagoga, } \\
\text { escritora, } \\
\text { docente } \\
\text { investigadora }\end{array}$ & $\begin{array}{l}\text { Sobresale en la docencia e investigación } \\
\text { educativa. } \\
\text { Pionera en inclusión educativa. } \\
\text { Gran aporte de literatura académica sobre } \\
\text { métodos de enseñanza. }\end{array}$ \\
\hline 6 & $\begin{array}{l}\text { Laura } \\
\text { Cabrera } \\
1983)\end{array}$ & $\begin{array}{l}\text { Docente, } \\
\text { periodista, } \\
\text { dirigente } \\
\text { social }\end{array}$ & $\begin{array}{l}\text { Crea el Frente de Mujeres Socialistas. } \\
\text { Dirigente de la Confederación de } \\
\text { Trabajadores del Ecuador. } \\
\text { Presidenta del Partido Socialista Ecuatoriano. } \\
\text { Cofundadora del Partido Socialista } \\
\text { Revolucionario Ecuatoriano (1963). }\end{array}$ \\
\hline 7 & $\begin{array}{l}\text { Lidia Noboa (1919- } \\
\text { 2012) }\end{array}$ & $\begin{array}{l}\text { Maestra, } \\
\text { pianista, } \\
\text { compositora }\end{array}$ & $\begin{array}{l}\text { Condecoración al Mérito Cultural Matilde } \\
\text { Hidalgo de Procel. } \\
\text { Creó material para estudiantes del } \\
\text { Conservatorio. } \\
\text { Enseñó, transcribió y compuso música } \\
\text { nacional y local en el Conservatorio. }\end{array}$ \\
\hline 8 & $\begin{array}{l}\text { María } \\
\text { Carrillo } \\
\text { 1981) }\end{array}$ & $\begin{array}{l}\text { Pedagoga, } \\
\text { filósofa }\end{array}$ & $\begin{array}{l}\text { Primera Subsecretaria de Educación del } \\
\text { Ecuador. } \\
\text { Fundó y fue la primera rectora del colegio "24 } \\
\text { de Mayo" y "Colegio de América". }\end{array}$ \\
\hline
\end{tabular}




\begin{tabular}{|c|c|c|c|}
\hline 9 & $\begin{array}{l}\text { María Angélica } \\
\text { Idrobo (1890-1956) }\end{array}$ & $\begin{array}{l}\text { Maestra, } \\
\text { escritora }\end{array}$ & $\begin{array}{l}\text { Cofundadora de la sociedad feminista Luz de } \\
\text { Pichincha. } \\
\text { Creó la Escuela Nocturna para Señoritas. }\end{array}$ \\
\hline 10 & $\begin{array}{l}\text { María Luisa Gómez } \\
\text { de la Torre (1887- } \\
\text { 1977) }\end{array}$ & $\begin{array}{l}\text { Educadora, } \\
\text { feminista }\end{array}$ & $\begin{array}{l}\text { Primera profesora en trabajar en un colegio de } \\
\text { varones. } \\
\text { Formó el Club de profesores del Mejía, } \\
\text { antecedente de la Unión Nacional de } \\
\text { Educadores. } \\
\text { Parte del partido Socialista Ecuatoriano, } \\
\text { Organización de Mujeres del Ecuador, Unión } \\
\text { democrática de Mujeres, Alianza Femenina } \\
\text { Ecuatoriana, Federación Ecuatoriana de } \\
\text { Indios (FEI). } \\
\text { Cofundadora de las primeras escuelas } \\
\text { indígenas. }\end{array}$ \\
\hline 11 & $\begin{array}{l}\text { Piedad } \\
\text { Serrano } \\
2010)\end{array}$ & $\begin{array}{l}\text { Educadora, } \\
\text { médica, } \\
\text { feminista }\end{array}$ & $\begin{array}{l}\text { Primera mujer azuaya en tener título de } \\
\text { Doctora. } \\
\text { Fundó el Colegio } 29 \text { de Marzo como apoyo a } \\
\text { trabajadores. } \\
\text { Creadora del movimiento } 8 \text { de marzo (primera } \\
\text { organización feminista de Azuay). }\end{array}$ \\
\hline 12 & $\begin{array}{l}\text { Piedad Peñaherrera } \\
\text { Araque (1929-1994) }\end{array}$ & $\begin{array}{l}\text { Catedrática, } \\
\text { antropóloga, } \\
\text { periodista }\end{array}$ & $\begin{array}{l}\text { Ganadora del premio Tobar en Ciencias } \\
\text { Sociales ( } 2 \text { ocasiones). } \\
\text { Cofundadora y catedrática de la Escuela de } \\
\text { Antropología y Etnología de la Universidad } \\
\text { Católica del Ecuador. }\end{array}$ \\
\hline 13 & $\begin{array}{l}\text { Raquel } \\
\text { Morales } \\
\text { 2018) }\end{array}$ & $\begin{array}{l}\text { Educadora, } \\
\text { académica } \\
\text { feminista, } \\
\text { historiadora }\end{array}$ & $\begin{array}{l}\text { Material académico y publicaciones sobre } \\
\text { aportes y mujeres importantes en Ecuador y } \\
\text { América Latina. }\end{array}$ \\
\hline 14 & $\begin{array}{lr}\text { Raquel } & \text { Verdesoto } \\
\text { Salgado } & (1910- \\
1999) & \end{array}$ & $\begin{array}{l}\text { Educadora, } \\
\text { escritora, } \\
\text { feminista }\end{array}$ & $\begin{array}{l}\text { Cofundadora de Alianza Femenina } \\
\text { Ecuatoriana y Mujeres del Ecuador. } \\
\text { Profesora honoraria de la Universidad Central } \\
\text { del Ecuador. }\end{array}$ \\
\hline 15 & $\begin{array}{l}\text { Rita Lecumberri } \\
(1831-1910)\end{array}$ & $\begin{array}{c}\text { Maestra, } \\
\text { poeta }\end{array}$ & $\begin{array}{l}\text { Ganadora del concurso literario en la } \\
\text { Municipalidad de Guayaquil (1883). } \\
\text { Creó una escuela nocturna en su hogar. }\end{array}$ \\
\hline
\end{tabular}

Fuente: Adaptado de Corral et al. (2021). 100 mujeres de nuestra Historia Ecuador. Kynku

Cada una de las mujeres mencionadas en la Tabla 6, se ha ganado un sitio en la historia ecuatoriana y profundo reconocimiento por ser pioneras, fundadoras, luchadoras y 
colaboradoras constantes en la construcción de un país y educación diferentes, es sin duda alguna, una de las mayores características que comparten. Es importante recalcar que la tabla presentada debe ser ampliada mucho más, pues es más que seguro que varias mujeres que han aportado significativamente a la sociedad en general y a la educación en particular, no están tomadas en consideración.

La comprensión de la historia de las mujeres debe cambiar su enfoque, pues no se trata de una integración a dicha historia, sino donde todas las personas tengan su propio papel protagónico (Zaragoza, 2015, p. 359). Al hablar de mujeres e historia es preciso aclarar que no solamente se busca que se las nombre de manera superficial como parte de los sucesos históricos, si no que se pretende crear las condiciones para que la historia sea concebida, comprendida e interpretada como la interacción y participación de mujeres y hombres como principales actores de los acontecimientos históricos y sociales.

\section{ESTRATEGIAS METODOLÓGICAS}

\section{A continuación, se describe la metodología utilizada en la investigación.}

- Enfoque: El estudio tiene un enfoque cualitativo y de carácter reflexivo donde la búsqueda de información documental se considera prioritario.

- Nivel de profundidad: Su nivel de profundidad es descriptivo, se maneja la información que permite caracterizar la problemática planteada.

- Tipo de investigación: La investigación es documental, que se basa en la selección, procesamiento y ordenamiento de información disponible en varias fuentes documentales.

- Técnicas e instrumentos: Se utilizó la técnica del fichaje con fichas trabajo diseñadas para incorporar el análisis crítico o punto de vista de los investigadores.

- Técnica de procesamiento de información: Se utilizó el análisis de contenido, la misma que se incorpora en el análisis y discusión de resultados.

\section{RESULTADOS Y DISCUSIÓN}

La investigación aborda dos elementos, por un lado, la feminización y por otro la docencia para responder a la pregunta central del ¿Por qué existe feminización en el Magisterio ecuatoriano?, sin embargo, a lo largo del abordaje investigativo se analizan elementos conceptuales que valen ser mencionados.

El proceso de feminización del Magisterio ecuatoriano es el resultado factores económicos, políticos, sociales, culturales y educativos, puesto que responde a realidades 
específicas. Es importante comprender el proceso de feminización en toda su complejidad, dicho esto, concebirlo como algo puramente positivo sería caer en una equivocación, es necesario analizarla en su contexto, así, la feminización docente si bien es cierto significa la predominancia femenina y la intervención en el mundo educativo nacional; guarda una parte no tan positiva, pues está ligada directamente con el grado de involucramiento dentro del escenario laboral educativo, así como con la valía de la profesión. Como afirma Araya (2004) “en los niveles de preescolar y de primaria, la gran mayoría de docentes son mujeres; no obstante, la proporción de estas disminuye a medida que aumenta la edad de las alumnas y alumnos y el prestigio social de cada ciclo escolar" (p. 6). Entonces, la feminización docente se relaciona de manera estrecha con los niveles educativos donde se ejerce la profesión y con el prestigio profesional. La ejemplificación más clara de desequilibrio dentro de la docencia es el nivel inicial, pues, aunque mujeres representan el 98\% no es sinónimo de revalorización profesional o de igualdad laboral, dentro de este suceso se genera a la par una vulneración hacia la población masculina con inclinación o interés por ejercer la pedagogía en niveles iniciales.

Los roles de género, las etiquetas y los estereotipos juegan un papel fundamental dentro del comportamiento "adecuado" de hombres y mujeres a lo largo de los años, como afirma Kaplan (2009) "Las etiquetas o pre-juicios (juicios previos, tácitos) se asocian al proceso de estigmatización y funcionan allí como metáforas sociales que simbolizan lo marginal" (p. 17). Generar prejuicios o categorizar a las personas, son solo una pequeña muestra del verdadero alcance de estos elementos que usualmente pasan desapercibidos en la cotidianeidad, pero que cubren todo accionar humano limitando y sesgando accionares.

Resaltar el proceso que se ha gestado dentro del Magisterio nacional para llegar a la actual feminización docente es sumamente importante. Con el triunfo de la Revolución Liberal dirigida por el General Eloy Alfaro se incluye a las mujeres en el campo educativo y laboral, en el primer campo se les permite recibir una educación pública, regular y laica, así como ser admitidas en programas académicos del país; en el campo laboral, con la creación de los normales, mujeres de todo el país pueden formarse como profesoras e ingresar al Magisterio nacional, proceso que se mantiene hasta nuestros días.

Según datos publicados por el (Ministerio de Educación, 2021) desde el periodo 19931994 hasta el período 2019-2020, del total de docentes por sexo, se mantiene la tendencia 
mayoritaria de docentes mujeres con relación a los hombres, lo que corresponde aproximadamente al $65 \%$ a nivel nacional.

\section{CONSIDERACIONES FINALES}

La feminización docente resulta de componentes económicos, históricos, sociales y culturales guiados a su vez por roles, estereotipos y etiquetas, pues son los dinamizantes para que todo el proceso se arme y ejecute, desembocando en la llamada feminización de la docencia dentro del Magisterio ecuatoriano.

En el nivel inicial, donde se trabaja con niñas y niños, se evidencia una mayoría absoluta de docentes mujeres, porque se lo concibe como extensión del trabajo de cuidado doméstico, un espacio socioafectivo que va a permitir potenciar sus capacidades y habilidades para la vida.

El ingreso de mujeres a la plataforma educativa parte con el mero hecho de la apertura de oportunidad de educación femenina y se consolida con la creación de Normales destinados a ser el alma mater de maestras. Desde el inicio aportes de profesoras a la educación y sociedad ecuatoriana en general han sido varios, pero, la difusión y reconocimiento ha quedado en el olvido; mujeres como Piedad Moscoso, Raquel Verdesoto, María Angélica Idrobo, Luisa Gómez de la Torre, en fin, mujeres que marcaron historia merecen ser reconocidas y recordadas por el arduo trabajo en pro de las mejoras de toda la sociedad, y es deber de todos el mantener fresca en la memoria sus aportes y contribuciones.

Es necesario generar condiciones para que mujeres y hombres tengan igualdad de oportunidades y de trato en el campo laboral y profesional, sin discriminación y exclusión, en ejercicio pleno de sus derechos establecidos en las diferentes normas jurídicas constitucionales y legales vigentes en el Ecuador.

\section{LISTA DE REFERENCIAS}

Abduca, L., Perez, V., \& Ainora, J. (2007). La violencia invisible: La "normalización" del castigo en los procesos de socialización. Buenos Aires: IV Jornadas de Jóvenes Investigadores. Instituto de Investigaciones Gino Germani, Facultad de Ciencias Sociales, Universidad de Buenos Aires. Retrieved from https://www.aacademica.org/000-024/42.pdf

Aguilar, P. (2011, enero). La feminización de la pobreza: conceptualizaciones actuales y potencialidades analíticas. Florianópolis, 14(1), 126-133. Retrieved from 
https://www.scielo.br/j/rk/a/M7zzFssbz6WFhLhTbPpB6DH/?lang=es\&format= pdf

Almeida, S., \& de la O Barroso, M. (2020). Equidad de género en docentes líderes dela Universidad Central del Ecuador, en el contexto del Objetivo de Desarrollo Sostenible 5. Estudios de la Gestión. Revista internacional de administración(8), 101-129.

Araya, S. (2004, octubre-noviembre). Hacia una educación no sexista. Revista Electrónica “Actualidades Investigativas en Educación”, 4(2), 1-13. Retrieved from https://revistas.ucr.ac.cr/index.php/aie/article/view/9088/17486

Banco Mundial. (2018). Educación. Retrieved from Banco Mundial: https://www.bancomundial.org/es/topic/education/overview\#1

Calderón, C., Racines, M., Castañeda, G. y Rodríguez, F. (2021). Análisis de las condiciones laborales del magisterio ecuatoriano durante la pandemia Ciencia Latina Revista Científica Multidisciplinar. Edición Enero-Febrero, 2021, Volumen 5, Número 1. http://ciencialatina.org/

Cappi, L., do Horto, M., \& Cappi, L. (2018). Docencia masculina en la educación infantil: discurso de negación de la comunidad escolar. Subjetividad y Procesos Cognitivos, 22(2), 81-104. Retrieved from http://www.scielo.org.ar/pdf/spc/v22n2/v22n2a07.pdf

Cook, R., \& Cusack, S. (2009). Estereotipos de género. Perspectivas Legales Transnacionales. Pennsylvania: University of Pennsylvania Press. Retrieved from https://www.law.utoronto.ca/utfl_file/count/documents/reprohealth/estereotiposde-genero.pdf

Corral, C., Vásquez , R., Dután , G., Escandón, T., \& Barros , K. (2021). 100 mujeres de nuestra historia Ecuador (2 ed.). Cuenca: Kynku.

Ferreira, C., García, K., Macías, L., Pérez, A., \& Tomsich, C. (2014). Mujeres y hombres del Ecuador en cifras III. Serie información estratégica. Quito: CNIG. Obtenido de Comisión de Transición hacia la Definición de la Institucionalidad Pública que garantice la Igualdad entre Hombres y Mujeres. Instituto Nacional de Estadística y Censos. ONU Mujeres. ISBN: 978-9942-07-390-7: http://repositorio.iaen.edu.ec/handle/24000/4470 
Gil, M. (2016, enero 06). La mujer y su rol en el desarrollo de las sociedades. Retrieved from Ágora, inteligencia colectiva para la sostenibilidad: https://www.agorarsc.org/la-mujer-y-su-rol-en-el-desarrollo-de-las-sociedades/

Graña, F. (2008, enero). El asalto de las mujeres a las carreras universitarias "masculinas": cambio y continuidad en la discriminación de género. Praxis educativa(12), 77-86. Retrieved from https://www.redalyc.org/pdf/1531/153112902008.pdf

Herrera, P. (2000, noviembre-diciembre). Rol de género y funcionamiento familiar. Revista Cubana de Medicina General Integral, 16(6), 569-573. Retrieved from Revista Cubana de Medicina General Integral. V.16. Scielo: http://scielo.sld.cu/pdf/mgi/v16n6/mgi08600.pdf

Kaplan, C. (2009). La asignación de etiquetas. La construcción social del "alumno violento". XII Simpósio Internacional de Processo Civilizador. Brasil: Recife. Retrieved from http://www.uel.br/grupoestudo/processoscivilizadores/portugues/sitesanais/anais12/artigos/pdfs/mesas_r edondas/MR_Kaplan.pdf

León, A. (2007). Qué es la educación. Educere. Revista Venezolana de Educación, 11(39), 595-604. Retrieved from https://www.redalyc.org/pdf/356/35603903.pdf Macías, N., \& Cedeño, R. (2014, noviembre 24). La inserción de las mujeres en el mercado laboral. Revista ECA Sinergia. Facultad de Ciencias Administrativas y Económicas, 5(5), 1-8. Retrieved from Revista ECA Sinergia. Facultad de Ciencias Administrativas y Económicas. U.T.M. Año 5 Vol. 5.: https://dialnet.unirioja.es/descarga/articulo/6197588.pdf

Ministerio de Educación. (2021). Base de datos. Retrieved septirmbre 1, 2021, from Educacion.gob.ec: https://educacion.gob.ec/base-de-datos/

Organización de las Naciones Unidas para la Educación la Ciencia y la Cultura UNESCO. (2013, abril 25). Docentes. Retrieved agosto 25, 2021, from UNESCO: https://es.unesco.org/themes/docentes

Rodríguez, N., \& Monllau, T. (2012, Octubre). La feminización de las profesiones. $\begin{array}{llll}\text { Revista } & \text { Sistema(228), } & \text { 81-96. } & \text { Retrieved }\end{array}$ http://diposit.ub.edu/dspace/bitstream/2445/105122/1/618468.pdf 
Saleh, L. (2005). La inclusión desde la mirada internacional. In M. d. Ministerio del Trabajo, Seminario internacional "Inclusión Social, Discapacidad y Políticas Públicas” (pp. 9-19). Santiago: Litografía Valente. Retrieved from https://www.unicef.cl/archivos_documento/200/Libro\%20seminario\%20internac ional\%20discapacidad.pdf

Vaca, L. (2019). Oportunidades y desafios para la autonomía de las mujeres en el futuro escenario del trabajo. Serie Asuntos de género No. 154. Santiago: Naciones Unidas. Retrieved from Naciones Unidas CEPAL. Serie Asuntos de Género N ${ }^{\circ}$ 154. ISSN:

1564-4170.:

https://repositorio.cepal.org/bitstream/handle/11362/44408/4/S1801209_es.pdf

Vásquez, P. (2010). La feminización de las profesiones sanitarias. Madrid: fundación BBVA.

Zaragoza, S. (2015). Aportes a la historia de las mujeres. Andamios, 12(27), 359-364. 